emphysema. Clinicopathological study of three further cases. Am J Surg Pathol. 1995; 19:563-70.

9. Hochholzer L, Moran C, Koss MN. Pulmonary lipomatosis: a variant of placental transmogrification. Mod Pathol. 1997;10:846-9.

10. Kronz JD, Palmer C, Askin FB. Images in pathology. Placental transmogrification of the lung. Arch Pathol Lab Med. 1999;123:856.
11. Marchevsky AM, Guintu R, Koss M, Fuller C, Houck W, McKenna RJ Swyer-James (Macleod) syndrome with placental transmogrification of the lung: a case report and review of the literature. Arch Pathol Lab Med. 2005;129:686-9.

12. Mark EJ, Muller KM, McChesney T, Dong-Hwan S, Honig C, Mark MA Placentoid bullous lesion of the lung. Hum Pathol. 1995;26:74-9.

\title{
Surgical correction of postpneumonectomy-like syndrome in a patient with a tuberculosis-destroyed lung
}

\author{
Yongjik Lee, MD, ${ }^{\text {a }}$ Hong Kwan Kim, MD, ${ }^{\text {b }}$ Seunghoon Lee, MD, ${ }^{\mathrm{b}}$ Hojoong Kim, MD, ${ }^{\mathrm{b}}$ and Jhingook Kim, MD, ${ }^{\mathrm{b}}$ Seoul, Korea
}

$\mathrm{P}$ ostpneumonectomy syndrome is a rare condition that is characterized by dyspnea resulting from an extreme mediastinal shift and bronchial compression of the residual lung after right or left pneumonectomy. ${ }^{1-3}$ Severe fibrosis of the lung such as is seen in a lung destroyed by tuberculosis (TB) can cause similar clinical features in the absence of pneumonectomy. ${ }^{4}$

We report here a couple of unique cases of postpneumonectomy syndrome without pneumonectomy in which treatment via pneumonectomy and mediastinal repositioning with tissue expanders was successful.

\section{Clinical Summaries}

PAtiEnt 1. A 47-year-old woman had had severe progressive dyspnea for 6 months. She had had pulmonary TB 20 years earlier, which was completely cured by administration of anti-TB drugs. On physical examination, breath sounds were decreased in the left lung field. A simple chest radiograph and computed tomogram (Figure 1, $A$ ) revealed that the left lung was almost completely destroyed and the right main bronchus was compressed by the right main pulmonary artery and the vertebral body.

The operation was performed via a left posterolateral thoracotomy. The severe pleural adhesion was dissected, and then left pneumonectomy was performed followed by insertion of two types of tissue expanders into the pleural cavity. One expander was ellipsoid $(350 \mathrm{~mL})$ and the other was crescent shaped $(250 \mathrm{~mL})$. After insertion of the tissue expanders, normal saline that included antibiotics

From the Department of Thoracic and Cardiovascular Surgery, Asan Medical Center, University of Ulsan College of Medicine, ${ }^{\text {a }}$ and the Department of Thoracic and Cardiovascular Surgery, Samsung Medical Center, Sung-

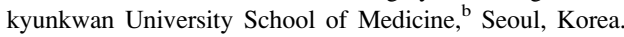

Received for publication Sept 13, 2007; revisions received Nov 19, 2007; accepted for publication Dec 27, 2007.

Address for reprints: Jhingook Kim, MD, Department of Thoracic and Cardiovascular Surgery, Samsung Medical Center, 50 Ilwon-Dong, Kangnam$\mathrm{Ku}$, Seoul, 135-710, Korea (E-mail: jkim@smc.samsung.co.kr).

J Thorac Cardiovasc Surg 2008;136:780-1

$0022-5223 / \$ 34.00$

Copyright (C) 2008 by The American Association for Thoracic Surgery doi:10.1016/j.jtcvs.2007.12.035 was injected into the tissue expanders, and the thoracotomy wound was closed.

Postoperatively, she recovered without any problem. A plain chest radiograph showed that the mediastinum had returned to a normal position (Figure $1, B$ ). In addition, the expiratory wheezing and dyspnea disappeared.

The patient was discharged from the hospital on the 13th postoperative day. At present, 4 years after the operation, she is being observed at the outpatient department and is without dyspnea.

PAtient 2. A 50-year-old woman had had severe progressive exertional dyspnea for the previous 6 months. She had had pulmonary TB 30 years earlier, which was completely cured by anti-TB medication. Six months before her current admission, the right lung totally collapsed and she had paroxysmal severe exertional dyspnea, which led her to visit our hospital's emergency room. On physical examination, there was no audible breath sound in the right side of the chest. Chest computed tomography revealed a totally collapsed right lung, extreme deviation of the mediastinal structure, and a narrowed left main bronchus, which was compressed between the left main pulmonary artery and the descending aorta (Figure 2, $A$ ). We performed a right pneumonectomy via a posterolateral thoracotomy. There was no pleural adhesion. Two types of tissue expanders were inserted, with $320 \mathrm{~mL}$ of normal saline being infused into the ellipsoid one and $450 \mathrm{~mL}$ into the crescentshaped one.

Postoperatively, the mediastinum returned to the normal position (Figure 2,B). The patient was discharged on the seventh postoperative day. Five months after the operation, she remains free of expiratory stridor and dyspnea on exertion.

\section{Discussion}

Postpneumonectomy syndrome is a rare complication that is characterized by tracheal stenosis and severe dyspnea; these symptoms are caused by mediastinal shifting after pneumonectomy. In the cases we presented, the right or left main bronchus was compressed between the main pulmonary artery and vertebra/aorta not by surgical pneumonectomy, but by auto-pneumonectomy that was due to TB. These 2 cases show that surgical pneumonectomy is not a prerequisite for postpneumonectomy syndrome because this malady occurs as a result of stenosis of the bronchus after vigorous movement and rotation of the mediastinum. 


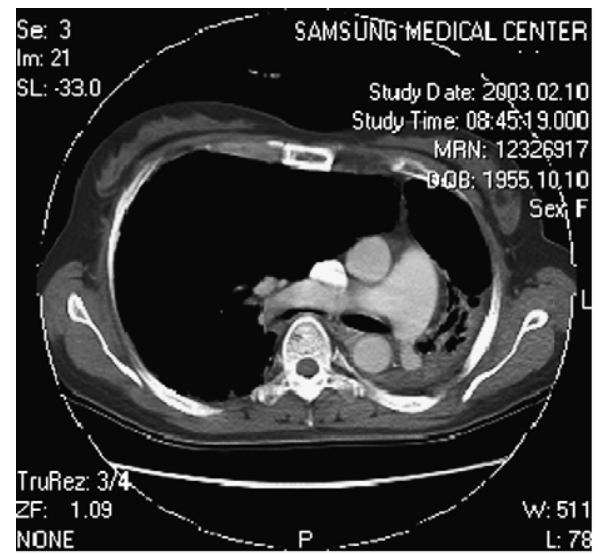

A

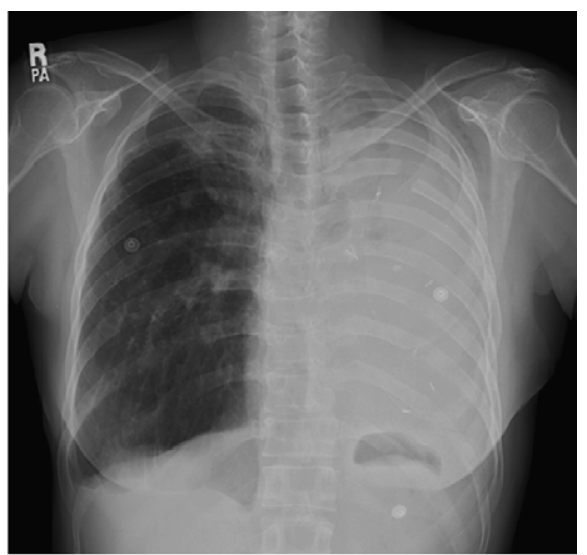

B
Figure 1. A, Preoperative chest computed tomogram shows narrowing of the right main bronchus compressed between the right main pulmonary artery and thoracic vertebral body. B, Postoperative chest radiograph shows the mediastinum in its normal position.
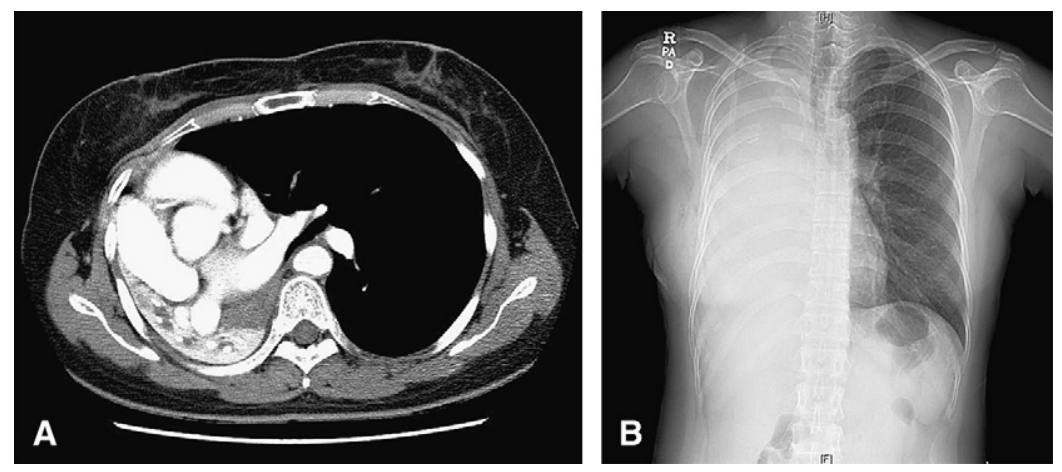

Figure 2. A, Preoperative chest computed tomogram shows narrowing of the left main bronchus compressed between the left main pulmonary artery and descending aorta. B, Postoperative chest radiograph shows the mediastinum in its normal position.

The diagnostic approach for our cases was the same as that for postpneumonectomy syndrome. On a plain chest radiograph, the mediastinum and bronchi are shifted posterolaterally and the opposite lung is herniated toward the lesion. Computed tomography of the chest can reveal that the heart and the great vessels are rotated toward the lesion and the bronchi are compressed by the vertebra and the great vessels.

Many methods have been tried to treat this syndrome. The most favorable method is insertion of tissue expanders in the hemithorax to shift the mediastinum to the midline and alleviate the obstruction of the trachea. Pneumonectomy must precede repositioning of the mediastinum by insertion of one or more tissue expanders in the case of a TB-destroyed lung without surgical pneumonectomy.

In conclusion, postpneumonectomy syndrome must be considered in the differential diagnosis when patients exhibiting dyspnea have a TB-destroyed lung or a reduced lung volume that is caused by severe pulmonary fibrosis. Once this syndrome is diagnosed, me- diastinal repositioning by insertion of one or more tissue expanders can be expected to lead to successful treatment.

\section{References}

1. Grillo HC, Shepard JAO, Mathisen DJ, Kanarek DJ. Postpneumonectomy syndrome: diagnosis, management, and result. Ann Thorac Surg. 1992; 54:638-51.

2. Shamji FM, Deslauriers J, Daniel JM, Matzinger FR, Mehran RJ, Todd TRJ. Postpneumonectomy syndrome with an ipsilateral aortic arch after left pneumonectomy. Ann Thorac Surg. 1996;62: 1627-31

3. Valji AM, Maziak DE, Shamji FM, Matzinger F. Postpneumonectomy syndrome: recognition and management. Chest. 1998;114:1766-9.

4. Veronesi G, Spaggiari L, Solli PG, Leo F, Villa G, Pastorino U. Postpneumonectomy-like syndrome after chemoradiation therapy for lymphoma. Ann Oncol. 2002;13:1945-7. 